\title{
Study of Arc-wire and Laser-wire processes for the realization of Ti-6Al-4V alloy parts
}

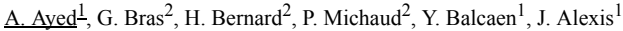

1 Laboratoire Génie de Production, INP-ENIT, 65016 Tarbes, France

2 Université de Bordeaux, ESTIA INSTITUTE OF TECHNOLOGY, F-64210 Bidart, France

Corresponding author: Joel Alexis, joel.alexis@enit.fr

\section{$\underline{\text { Abstract }}$}

Arc-wire or laser-wire additive manufacturing seems promising because it allows large parts to be produced with significant deposition rates (ten times higher than powder bed additive manufacturing), for a lower investment cost. These additive manufacturing techniques are also very interesting for the construction or the repair of parts. A versatile 3D printing device using a Wire Arc Additive Manufacturing (WAAM) station or laser device Wire Laser Additive Manufacturing (WLAM) for melting a filler wire is developed to repair and build large titanium parts. The final objectives of the study are to optimize the process parameters to control the dimensional stability, the metallurgical and mechanical properties of the produced parts. In this paper, an experimental study is carried out to determine the first order process parameter ranges (synergic law, laser power, wire feed speed, travel speed) appropriate for these two techniques, for repair or construction parts on Ti-6 Al-4V.

Keywords:

Ti-6Al-4V - Wire Arc Additive Manufacturing - Wire Laser Additive Manufacturing

\section{Introduction}

Additive Manufacturing (AM) often called 3D printing is a promising way to produce near-net shape metal parts with complex geometries and is nowadays among the most studied processes Additive Manufacturing offers many advantages compared to machining processes, as reductions in the manufacturing lead-time and cost due to low material waste [1]. The buy-to-fly ratio for a part machined from a forged billet is typically $10-20[2]$ and can potentially drop to nearly 1 when produced by AM techniques [3]. In addition, the use of these techniques (especially AM by wire) allows a high deposition rate [4] [5]. Therefore, AM techniques are relatively relevant and essential to developers to lower the production costs of parts in Ti-6Al-4V titanium alloy, which is one of the most expensive alloys, but also one of the most used in the aerospace industry, because its low density, its very good mechanical properties and its resistance to corrosion [6]. Whatever the additive layer manufacturing technologies used (powder-bed, powder-feed, wire-feed, or other processes), it is always based on an input model in the form of a three-dimensional CAD model, sliced into thin layers, which will be constructed by superimposing layers by the machine or robot to create the desired final part [7]. Complementary in the aerospace industry, wire-based additive manufacturing techniques have received much less attention than powder-bed techniques despite the increasing demand for these technologies, thanks to their significant potential, particularly for the construction of large pieces. In this paper, the operating ranges of the WAAM and WLAM processes are defined first, then the impact of the first order process parameters (most influential parameters [8]) on the geometry of single seams of Ti-6Al-4V deposits is studied.

\section{Material and experiments}

2.1 Wire Arc Additive Manufacturing (WAAM-CMT)

The cell is composed of a 6-axis robot (KUKA KR100-2 HA 2000) with its controller (KUKA KR C2). The chosen welding process is a derived MIG/MAG process developed by FRONIUS called CMT for Cold Metal Transfer (Fronius International GMBH 2018). This process used a welding station (FRONIUS TPS 3200 CMT Remote) and a wire feeder (FRONIUS VR 7000-CMT CMT for Cold Metal Transfer (Fronius International GMBH 2018). This process used a welding station (FRONIUS TPS 3200 CMT Remote) and a wire feeder (FRONIUS VR 7000-CMT weld bead against oxidation. The chamber design is based on the fact that argon is heavier than the air: by pushing argon continuously on the box bottom, the air is progressively expelled out of the chamber. Moreover, to avoid perturbation due to welding torch displacement and trapped oxygen the argon flow must be laminar and continuous. Concerning the deposition process, the synergy law 1007 from database R01-1663 (DB 0164) was used. The influence of the wire feed speed and the travel speed of the robot on the dimensional characteristics of the deposits was studied. For that purpose, we print 10 seams from 0.4 to $1.3 \mathrm{~cm} . \mathrm{s}^{-1}$ for travel speed of the robot (keeping WFS constant at $8.5 \mathrm{~m}_{\mathrm{min}} \mathrm{m}^{-1}$ ) and 10 seams from 6 to $10.5 \mathrm{~m} . \mathrm{min}^{-1}$ for the wire feed speed (keeping TS constant at $0.6 \mathrm{~cm} \cdot \mathrm{s}^{-1}$ ). The $120 \mathrm{~mm}$ long deposits were made on $150 \times 30 \times 10 \mathrm{~mm} 3 \mathrm{Ti}-6 \mathrm{Al}-4 \mathrm{~V}$ substrate. Before each deposition, a surface preparation is carried out on the substrate with mechanical water polishing (MD-Piano 220 disk) and subsequently cleaned with acetone.

\subsection{Wire Laser Additive Manufacturing (WLAM-LMD)}

The Cell is composed of a 6-axis robot (KUKA KR60-HA) with its controller (KUKA KRC4). The energy used to meld wire and substrate is coming from a $6 \mathrm{~kW}$ laser source (TRUMPH TruDisk 6001). The laser head mounted on the robot leads the laser beam through several lenses to obtain a focal spot which has the geometry of a ring (PRECITEC CoaxPrinter). The wire is conveyed at the centre of the ring spot thanks to a wire feeder (DIX WD 300). As for the CMT experiment, the Ti-6Al-4V wire is provided by Technalloy. Regarding the O2 protection the same inert chamber is used. Our experimental approach is to try a large set of parameters regarding the limitation of each hardware. The CORICO software is used to construct the experimental design [9]. In this study, the various parameters for the WLAM process are laser beam power (P), the wire feed speed (WFS) and the travel speed (TS). The ranges of variation are between 1 and $3.25 \mathrm{~kW}$ for the laser power, 0.8 and $6.4 \mathrm{~m} \cdot \mathrm{min}^{-1}$ for the wire flow and between 0.3 and $2.35 \mathrm{~m}_{\mathrm{min}} \mathrm{m}^{-1}$ for the robot speed. For these deposits, wire feed is initiated 0.2 second after the laser is set on, and the robot movement is started 0.1 second after. The process is therefore initiated about 0.3 seconds before the robot begins to move. The deposition was performed on similar shaped and prepared substrates.

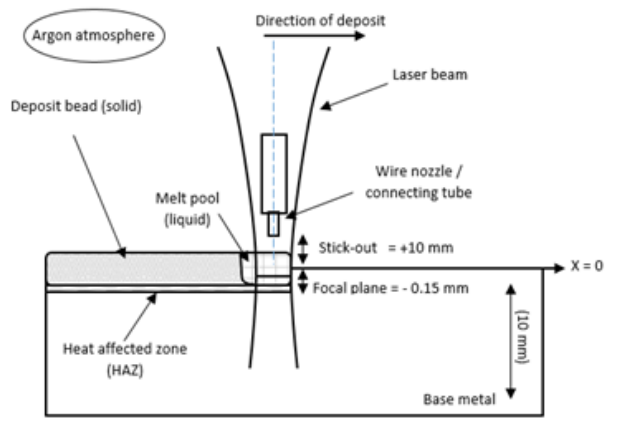

Figure 1: Schematic drawing of the Wire Laser Additive Manufacturing (WLAM) process

\subsection{Characterization techniques}

Scans of WAAM-CMT and WLAM-LMD deposits were performed with 3D ATOS scanner and analysed with CATIA V5 and ABviewer 14 software. All the seams obtained in WAAM and WLAM (120 mm long) were mechanically sectioned along the longitudinal direction from central part and two transverse direction at lengths of $40 \mathrm{~mm}$ and $80 \mathrm{~mm}$. The samples for the microstructural characterization were cut perpendicularly to the deposit line. The specimens were grounded with $600,1200,2500$ grit SiC paper under water, polished with an OPS solution with hydrogen peroxide to a mirror finish. They were then etched with the Kroll attack reagent composed of $3 \mathrm{~mL}$ of $40 \%$ hydrofluoric acid, $2 \mathrm{~mL}$ of $68 \%$ nitric acid and $95 \mathrm{~mL}$ of distilled water. The macro-structure (mooring angles, depths of remelted zones and heat affected zones) were observed by optical microscopy (Leica wild M420 binocular and Olympus PMG3 microscope) on polished and etched specimens.

\section{Results and discussion}

3.1 Operating area of WAAM and WLAM processes

(C) The Authors, published by EDP Sciences. This is an open access article distributed under the terms of the Creative Commons Attribution License 4.0 (http://creativecommons.org/licenses/by/4.0/). 
The figure 2 presents the different single deposits made by the WAAM and WLAM methods. Regarding the WAAM-CMT process, whatever the chosen parameters, single deposits were obtained (figure $2 \mathrm{a} \& \mathrm{~b}$ ). The parameters seem stable because the dimensions of the deposits do not vary over their entire length. Single deposits do not show any color which indicates a sufficient gas protection. Finally, a large number of projections around deposits is observed with the CMT process. On the other hand, it is quite different for the deposit obtained by WLAM process. The operating range of this process seems more restricted. Indeed, many defects are observed in the single deposit. In general, gaseous protection is not sufficient given the significant coloration of the single deposit (figure 2c). A modification of the inerting system was made to avoid oxidation. Experiments showed that the air blade which protects lenses of the CoaxPrinter head, called crossjet, induced $\mathrm{O}_{2}$ perturbation near the melt pool. That is why a special trailing gaseous shield has been designed. The inerting of the process is ensured by a local protection of the melt bath with an argon flow rate of $301 . \mathrm{min}^{-1}$ and a global protection of the process by argon overflow at a pressure of 1.5 bar (Figure 2d). The deposits obtained have a smooth surface with a bright metallic appearance free of oxidation.
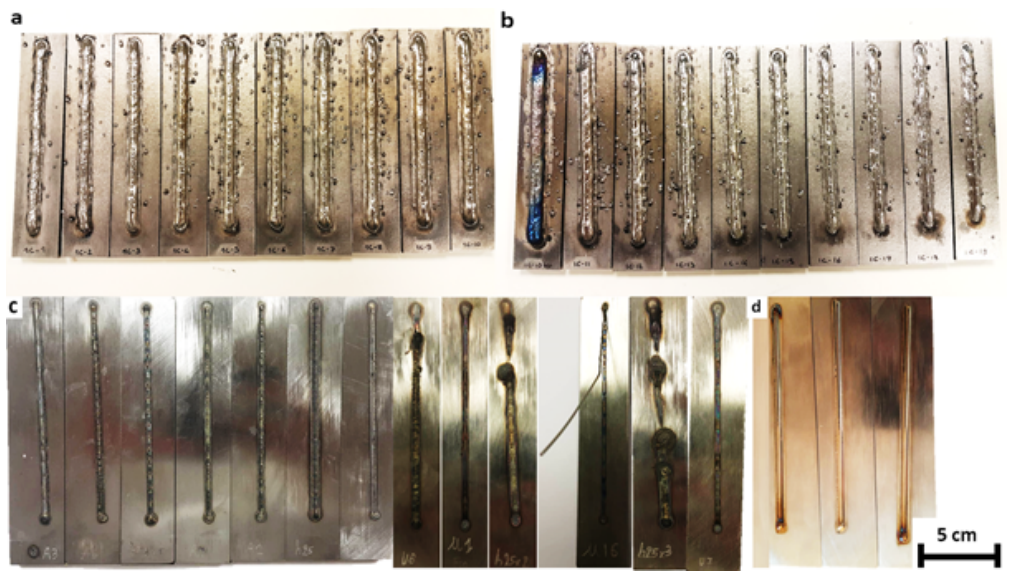

Figure 2 : Optical observation of the single deposits made by (a), (b) WAAM-CMT and (c),(d) WLAM

For certain conditions, no deposits are obtained. The fusion of the wire is initiated 0.2 seconds before the movement of the robot. Since the first drop of liquid metal is deposited before the robot head is moved, the different initiation ranges of the WAAM and WLAM processes have been determined according to the WFS and P parameters (Figure 3). For high power values and low wire feed speeds, a drop of liquid metal can be formed and rises by capillary action in the contact tube which
$\mathrm{kW}$ ), the deposit cannot form because the heat input energy is too low to melt the titanium wire

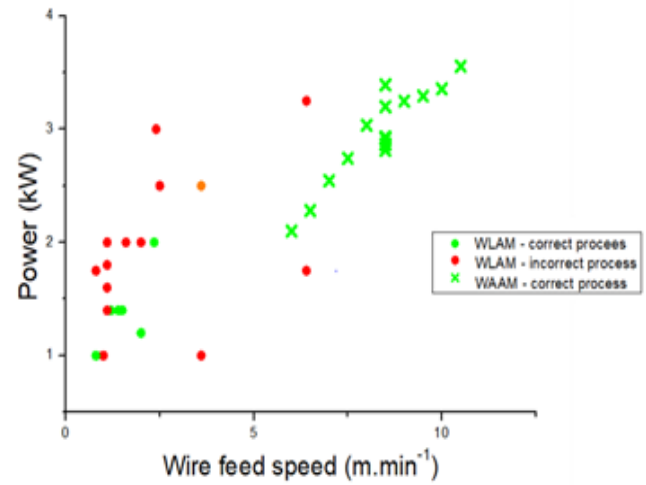

Figure 3 : Determination of the operating ranges for the initiation of the WAAM and WLAM processes

To explain the homogeneity of the WLAM deposits it is necessary to consider the heat input energy. The heat input energy parameter is integrated in the determination of the operating range of the enerated by the laser beam and the laser-material interaction time. The focal spot is of the outer fiber type, and its diameter was determined on the basis of a $1000 \mathrm{~W}$ shot during 200 milliseconds on an anodized aluminum substrate. The power density parameter is the ratio mean power divided by the surface of the spot. The operating area for the WLAM process is presented based on the WFS/P ratio and the heat input energy in Figure 3 . A minimum heat input energy of $12 \mathrm{~kJ} . \mathrm{cm}^{-2}$ and a WFS/P ratio close to 1 seems necessary to obtain a homogeneous deposit. If the WFS/P ratio is less than 1 , the wire is not sufficiently melted on the substrate. If this ratio is greater than 1 , the formation of liquid metal spheres which rise by capilarity in the contact tube is observed.

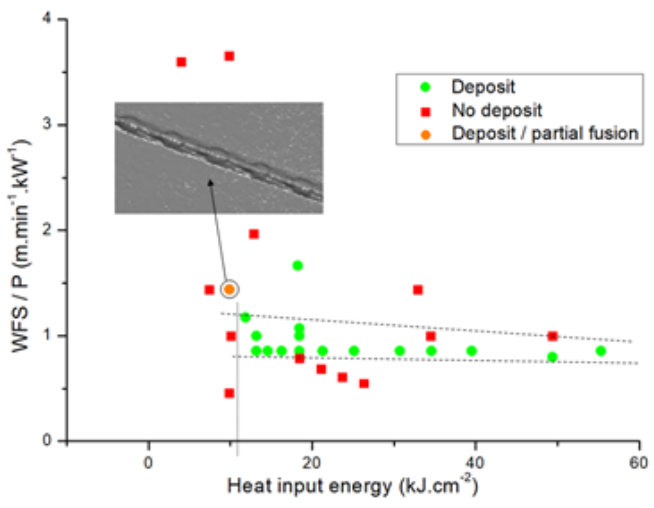

Figure 4 : Determination of the deposition operating ranges of the WLAM process for Ti-6Al-4V titanium alloy

The dimensions of the homogeneous deposits (width, height, wetting angle) were studied in relation to the robot's travel speed and the wire feed speed for the WAAM-CMT process (Figure 5) and depending on the travel speed of the robot for the WLAM process (Figure 6). First, the size of the deposits made by the WLAM process is much smaller than those obtained by the WAAM process, for the same range of robot's travel speed. A factor 3 exists between the deposit dimensions developed by these two processes. Whatever the process, the width and height of the single deposits decrease when the speed of the robot's travel speed increases. This result is consistent with those of Brandl et al. [10]. This decrease is more significant for the WAAM process. In fact, for travel 
speed values between 0.2 and $0.7 \mathrm{~m} \cdot \mathrm{min}^{-1}$, the width and height of the deposits decrease by 10 to $6 \mathrm{~mm}$ and 6 to $3 \mathrm{~mm}$, respectively. The width of the deposits made of WLAM decreases by 2,75 to $2.5 \mathrm{~mm}$ and the height from 2.1 to $1.3 \mathrm{~mm}$. These differences are explained by the higher energy density of the WAAM process.

Note that the increase of the process parameters (WFS and TS) does not affect the regularity of WAAM-CMT printed leads. On the contrary, for WLAM process, an increase in robot speed (at constant P and WFS) results in finer, lower, and less regular deposits as shown in Figure 6.
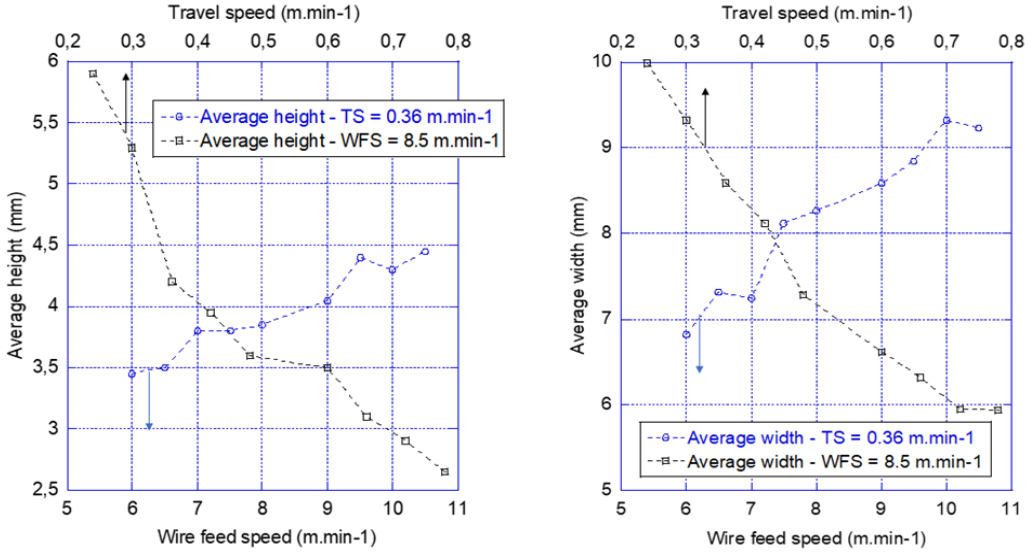

Figure 5 : Evolution of average width and height of deposits $(\mathrm{mm})$ according to travel speed $\left(\mathrm{m}^{\mathrm{m}} \mathrm{min}^{-1}\right)$ and wire feed speed $\left(\mathrm{m} \cdot \mathrm{min}^{-1}\right) /$ WAAM

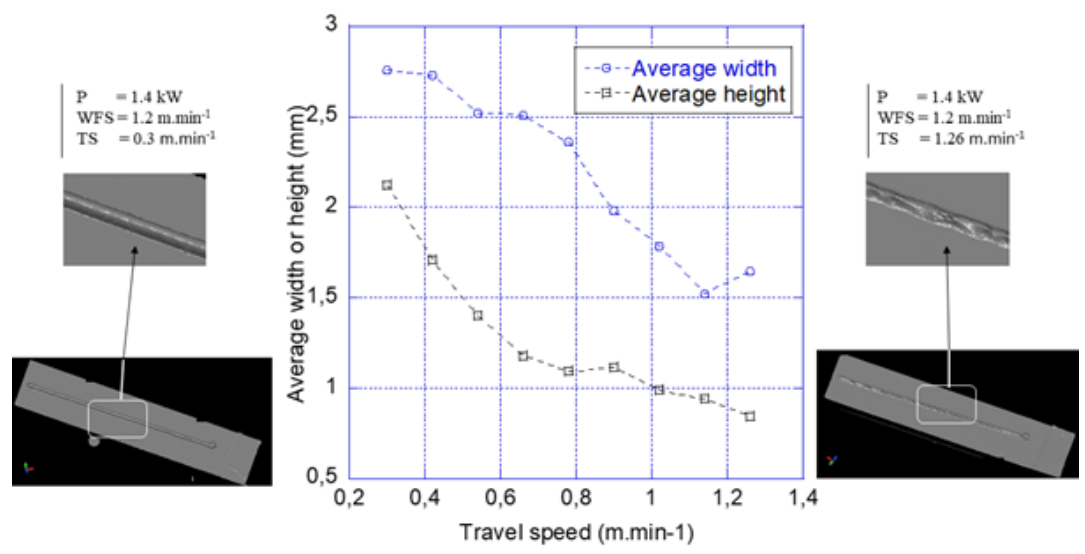

Figure 6 : Evolution of average width and height of deposits $(\mathrm{mm})$ according to travel speed $\left(\mathrm{m}^{\mathrm{m}} \mathrm{min}^{-1}\right)$ / WLAM

Robot speed also seems to have an impact on the wetting angles of the deposits for both technique of deposition. Indeed, an increase of this parameter generates deposits with increasingly large wetting angles. This is due to the fact that less and less material has been deposited for the same power density, making it easier to spread on the substrate.

Note that for all the seams deposited, the wetting angles $(\alpha)$ are all greater than $100^{\circ}$ (for WAAM and WLAM processes) (figure 7). Except for a single WLAM deposit elaborated at a power of 1.2 $\mathrm{kW}$, a wire feed speed of $2 \mathrm{~m} \cdot \mathrm{min}^{-1}$ and a travel speed of $0.78 \mathrm{~m} \cdot \mathrm{min}^{-1}$, the wetting angle is of the order of $60^{\circ}$. This single deposit corresponds to a bonded deposit, with only melting with the base metal.

3.3 Influence of the operating parameters on the macrostructure of the deposits

The study of the impact of a variation of travel speed on the size of the remelted zones (RZ) and the thermally affected zones (HAZ) is carried out (figure 7). By increasing the robot speed, we notice a decrease in the depths of the remelted zone and the heat affected zone for the two processes used (figure 8). These observations have been confirmed by Brandl et al. [10].
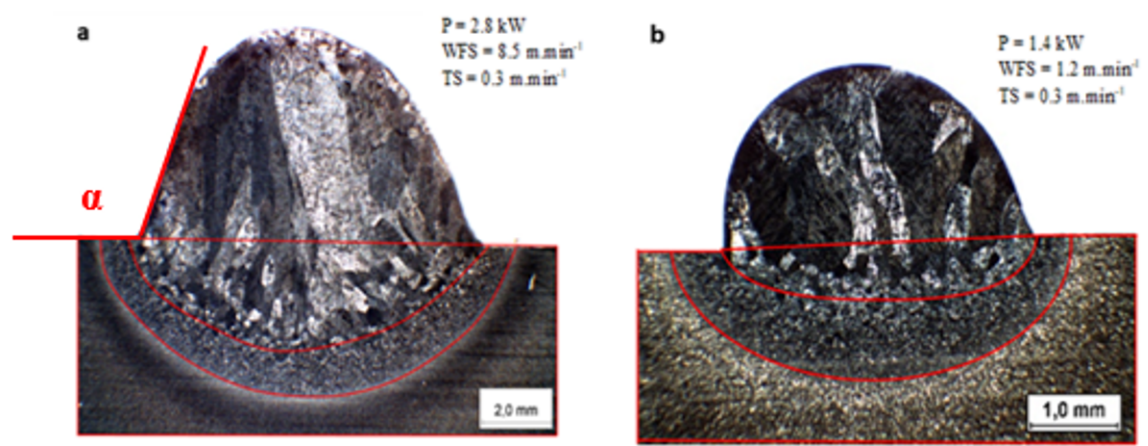

Figure 7 : Cross section micrographies of Ti-6AI-4V WAAM (a) and WLAM (b) deposits 

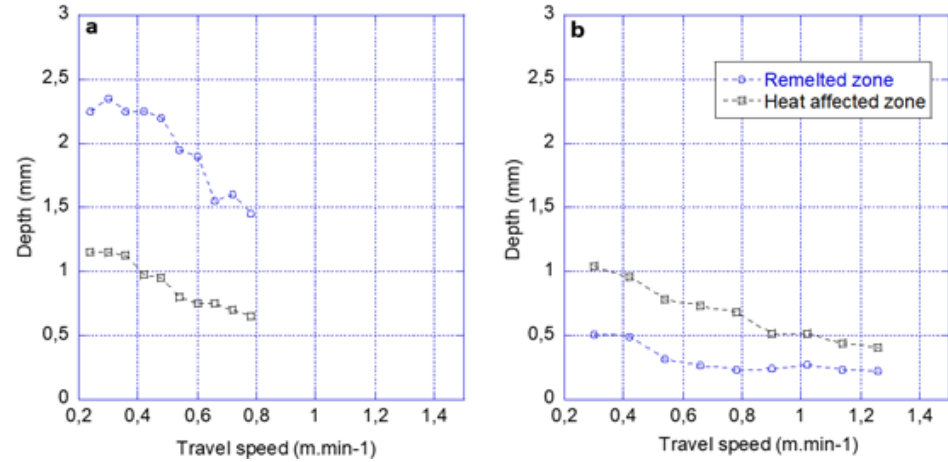

Figure 8 : Evolution of the depth of remelted and heat affected zone of WAAM deposits (a) and WLAM deposits (b) according to travel speed

The defects on the deposits obtained by WAAM and WLAM is then studied by optical microscopy according to the longitudinal and transverse sections. Some spherical porosities are observed. The origin of these porosities is probably largely due to small amounts of water remaining on the substrate after mechanical polishing to prepare the surface before deposition. In fact, during the process, a very high temperature is reached generating the decomposition the water in hydrogen, and this hydrogen no has time to escape from the melt and remains trapped in the liquid metal. This phenomenon may explain the few porosities in filiations found on the WAAM deposits, porosities aligned mainly at the end of the bead (at the end of the melting bath). Finally, a small part of these porosities could be associated with the argon process required to ensure inerting, argon which can also be trapped in the melting bath during deposits. It should be noted that the volume fraction of these porosities remains very low compared to the total surface area of the deposits. Only two spherical porosities of sizes equal to $46 \mu \mathrm{m}$ and $72 \mu \mathrm{m}$ were found in the 15 laser-wire deposits, while about thirty porosities were found in the twenty deposits printed by WAAM-CMT process, of sizes between $16 \mu \mathrm{m}$ and $375 \mu \mathrm{m}$.

\section{Conclusion}

The operating areas of the WAAM-CMT and WLAM processes were studied and determined to produce single Ti-6Al-4V titanium alloy deposits. This area appears to be more extensive for the WAAM process. Inerting systems have been developed to prevent oxidation of deposits. The evolution of the dimensions of the single deposits according to the parameters processes such as the travel speed of the robot's head, the wire feed speed or even the power has been established. Finally, the sizes of the melted and the thermally affected areas of the deposits were also determined according to the process parameters.

The WAAM process allows a larger amount of material to be deposited in order to obtain large single deposits. In view of the greater amount of energy used in this process, the depths of the melted and the thermally affected areas are greater. This process seems adapted for the deposition and repair of Ti-6Al-4V parts thanks to good geometrical characteristics and an important penetration into the base metal.

The use of WLAM process seems to be more difficult. The first results of this study are promising. They helped to define a working range for the process. Thinner deposits were obtained. The continuation of this WLAM study will focus on the exploration of larger P/WFS and TS ranges to study the applicability of this process under construction.

\section{Acknowledgments}

This work was financially supported by the Fonds Unique Interministériel (FUI Addimafil).

\section{References}

[1] W.E Frazier, Metal Additive Manufacturing: A Review. J mater Eng Perform 23, 6, (2014) 1917-1928

[2] H.M Flower, High Performance Materials: A review. J mater Eng Perform 23, 6, (2014) 1917-1928

[3] B.A.Szost, S. Terzi, F. Martina, D. Boisselier, A. Prytuliak, M. Hofmann, D.J. Jarvis, A comparative study of additive manufacturing techniques: Residual stress and microstructural analysis of CLAD and WAAM printed Ti-6Al-4V components. Materials and Design 89, (2016) 559-567

[4] D. Ding, Z. Pan, D. Cuiuri, H. Li, Wire-feed additive manufacturing of metal components: technologies, developements and future interest. Int J Adv Manuf technol, 81, 1-4, (2015) 465-481

[5] F. Martina, J. Mehnen, S.W. Williams, P. Colegrove, F. Wang, Investigation of the benefits of plasma deposition for the additive layer manufacturing of the Ti-6Al-4V. Journal of Materials Processing technology, 212, 6, (2012), 1377-1386

[6] M. Peters, J. Kumpfert, C.H. Ward, C. Leyens. Titanium Alloys for Aerospace Application, Advanced Engineering materials, 5, 6, (2003) 419-427

[7] E. Brandl, Microstructural and mechanical properties of additive manufactured titanium (Ti-6Al-4V) using wire, Shaker Verlag, Aachen, Germany, (2010)

[8] J. Larsson, Modeling of Laser Metal Deposition, Chalmers university of Technology, Sweden, (2016)

[9] M. Lesty : La revue de Modulad, 22, (1999) 41-77.

[10] E. Brandl, V. Michailov, B. Viehweger, C. Leyens, Deposition of Ti-6Al-4V using laser and wire, part II: Hardness and dimensions of single beads, Surface \& Coatings Technology, 206, (2011) $1130-1141$ 